
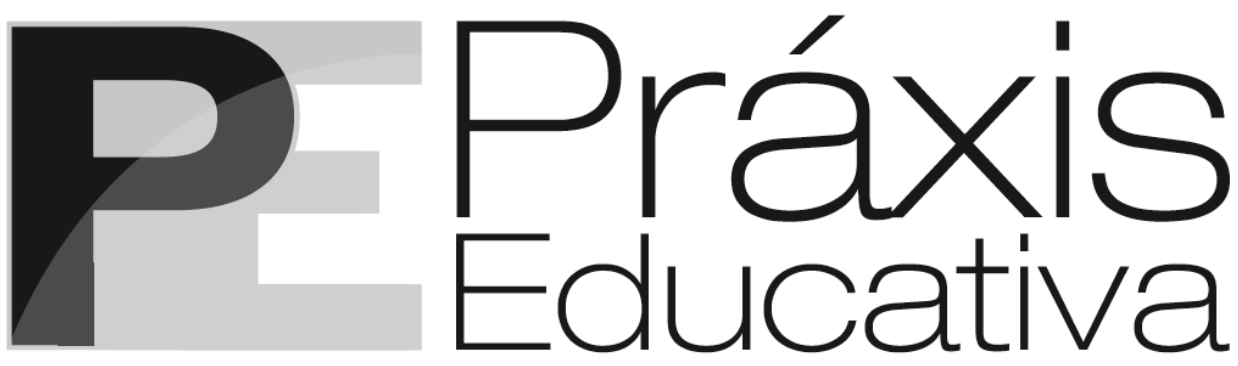

ISSN 1809-4309 (Versão online)

DOI: 10.5212/PraxEduc.v.12i2.0008

\title{
Educação Física escolar e políticas de inclusão: entre a gestão de riscos e o ensino
}

\section{Physical Education in schools and inclusion policies: between risk management and teaching}

\section{Educación Física en la escuela y políticas de inclusión: entre la administración de riesgos y la enseñanza}

Roseli Belmonte Machado*

\begin{abstract}
Resumo: Este artigo analisa as políticas de inclusão e a Educação Física escolar dentro da perspectiva baseada nos Estudos Foucaultianos em Educação. Por esse viés, entende-se que hoje a inclusão é um imperativo de Estado, inserindo-se numa grade de inteligibilidade que fomenta formas de regulação da vida e de controle dos riscos dos distintos indivíduos. O objetivo é o de discutir outras formas de olhar para as políticas de inclusão e a Educação Física escolar, a partir da análise dos documentos que as regulam. A metodologia da pesquisa é de inspiração genealógica, destacando uma apreciação dos discursos presentes nos documentos oficiais que legitimam essas políticas. Os resultados e conclusões indicam que a Educação Física escolar e as políticas inclusivas se enredam numa busca pela inclusão como gestão de riscos dos sujeitos, desconsiderando aspectos que se relacionam ao ensino.
\end{abstract}

Palavras-chave: Educação Física. Políticas de Inclusão. Estudos Foucaultianos.

Abstract: This paper analyzes inclusion policies and physical education in schools within the perspective of Foucauldian studies on Education. Under such perspective, inclusion is nowadays seen as a mandatory public issue, being inserted in an intelligibility agenda that promotes the regulation of life in society and risk control for different individuals. The objective is to discuss other ways of looking at inclusion policies and physical education in schools, from the analysis of official documents. Genealogical research was developed, focusing on the discourses presented in the official documents which legitimate such policies. Results and conclusions indicate that physical education in schools and inclusion policies are entangled in the search for inclusion as the individuals' risk management, disregarding aspects related to teaching.

Keywords: Physical education. Inclusion policies. Foucauldian studies.

Resumen: Este artículo analiza las políticas de inclusión y la educación física desde la perspectiva de los Estudios de Foucault en la Educación. En este sentido, se entiende que en la actualidad la inclusión es un imperativo del Estado, entrando en una polémica de inteligibilidad que fomenta formas de regulación de la vida y de control de los riesgos de los diferentes individuos. El objetivo es discutir otras formas de ver las políticas de inclusión y la educación física en la escuela, a partir del análisis de los documentos que los regulan. La metodología de la investigación es genealógica, haciendo hincapié en una apreciación del

\footnotetext{
*Professora da Universidade Federal do Rio Grande (FURG). E-mail: <robelmont@yahoo.com.br>.
} 
discurso actual en los documentos oficiales que legitiman estas políticas. Los resultados y las conclusiones indican que la educación física escolar y las políticas inclusivas están incorporadas en una búsqueda de temas de inclusión y de gestión de riesgos, haciendo caso omiso de los aspectos que se relacionan con la educación.

Palabras clave: Educación Física. Políticas de Inclusión. Los estudios de Foucault.

\section{Palavras iniciais}

Existem momentos na vida em que a questão de saber se se pode pensar diferentemente do que se pensa, e perceber diferentemente do que se vê, é indispensável para continuar a olhar on a refletir (FOUCAULT, 1994, p. 13).

As reflexões trazidas neste artigo referem-se a um modo de olhar e de analisar as políticas de inclusão e a Educação dentro de uma perspectiva pós-estruturalista - baseada nos Estudos Foucaultianos em Educação. Ao assumir essa perspectiva de pesquisa, alio-me a uma ideia de Filosofia da Prática, buscando empreender uma reflexão rigorosa de dentro do lugar em que estou. Implicada com trabalhos e pesquisas sobre a escola, a Educação Física e as políticas de inclusão, faço deste espaço uma manifestação das impressões que o olhar de dentro dessas questões me possibilitou. Partilho o desejo de, como traz a epígrafe desta seção, pensar diferente do que tenho visto e o tomo como uma possibilidade de continuar as reflexões que envolvem esses três temas.

$\mathrm{Na}$ companhia de outros autores ${ }^{1}$ que pesquisam as políticas de inclusão no âmbito dos Estudos Foucaultianos, concordo com Lopes e Fabris (2013) sobre a afirmação de que hoje a inclusão ocupa um status de "imperativo de Estado", inserindo-se numa grade de inteligibilidade que, dentre outros aspectos, promove a circulação dos sujeitos modificando seus modos de vida. Tais mudanças, contudo, não são desacompanhadas de formas de regulação e controle que intentam, dentre outras coisas, planejar a vida e controlar os riscos dos mais variados indivíduos. Não obstante, para Lopes e Veiga-Neto (2011), a inclusão toma forma e corpo na Contemporaneidade, adentrando as agendas políticas, econômicas e sociais. É um discurso que prolifera dos mais distintos modos, ganhando uma visibilidade e um status de verdade. Ao olharmos para o entorno, podemos ver as inúmeras campanhas produzidas em favor dessa política, ora por órgãos e agências ligadas ao Governo, ora pela iniciativa privada. Aparentemente, portanto, podemos pensar que a inclusão não discrimina ninguém. Todos são, de um modo ou de outro, capturados, gerenciados, controlados. As políticas de inclusão podem ser entendidas como "envolvidas com uma maior economia entre a mobilização dos poderes e a condução das condutas humanas" (VEIGA-NETO; LOPES, 2007, p. 955). Como trazem Lopes e Fabris (2013), a inclusão se apresenta, nos dias de hoje, como um imperativo capaz de promover a ampla circulação das pessoas, o borramento das fronteiras, a mobilização para o consumo e para a concorrência, a pretensa garantia dos direitos sociais, a benevolência e a caridade, dentre outras prerrogativas.

Dentro das escolas brasileiras, as práticas inclusivas para alunos com deficiência instalaram-se na década de 90 . Em um âmbito geral, as duas Declarações que impulsionaram a

\footnotetext{
${ }^{1}$ Lopes e Fabris (2013); Hattge (2014); Lockmann (2013); Menezes (2011); Rech (2010); Lopes e Hattge (2009); Gallo (2009); Veiga-Neto (2001); Lopes e Veiga-Neto (2007).
} 
ascensão das Políticas de Inclusão foram a Declaração Mundial sobre Educação Para Todos, de 1990, e a Declaração de Salamanca sobre Princípios, Política e Práticas na Área das Necessidades Educativas Especiais, de 1994. As prerrogativas de uma educação inclusiva são manifestas na LDB 9394/96 no artigo $4^{\circ}$, inciso III, como "O dever do Estado com educação escolar pública será efetivado mediante a garantia de atendimento educacional especializado gratuito aos educandos com deficiência, transtornos globais do desenvolvimento e altas habilidades ou superdotação, transversal a todos os níveis, etapas e modalidades, preferencialmente na rede regular de ensino". Para Lavergne (2009), os grandes difusores de todo esse discurso a respeito de diversidade e respeito às diferenças, são as grandes agências internacionais, tais como OMS, UNESCO, FMI e Banco Mundial, que operam dentro de uma forma de economia política neoliberal.

Segundo Foucault (2008), ao analisar as formas de neoliberalismo, no curso Nascimento da Biopolítica, ministrado no Collège de France em 1979, o ponto comum existente entre o econômico e o social é a não-exclusão; isso, para Lopes (2009), significa pensarmos que a inclusão é uma característica do neoliberalismo, na medida em que faz a manutenção de todos nas redes do mercado. De acordo com a autora, existem duas grandes regras que operam no jogo neoliberal: manter-se sempre em atividade e ter todos incluídos em diferentes níveis de participação. Para isso é necessário ser educado em direção a entrar no jogo, permanecer e desejar permanecer nele. Assim, compreendo a busca pela inclusão como uma estratégia que visa a posicionar e a conduzir os sujeitos dentro dessa racionalidade. Ao estarem no jogo, é preciso que cada um invista em seu capital humano, torne-se um empresário de si, responsável pelos cuidados consigo que antes eram de responsabilidade do Estado; é necessário ainda que se mobilize em empreendimentos sociais e se curve à inclusão como algo bom para todos. É um movimento que deve atingir a todos indistintamente e que se configura como um imperativo de Estado (LOPES; FABRIS, 2013).

Ao vermos que a inclusão é hoje um imperativo de Estado e que, de certo modo, se tornou uma prática irrefutável dentro das escolas, podemos considerar que todos os sujeitos participantes de uma comunidade escolar estão imersos nessa prerrogativa. Dentre estes, destaco para esta análise, os professores de Educação Física e suas práticas. Ao circularmos pelo ambiente escolar, percebemos como esses docentes se responsabilizam por fazer das práticas corporais um dos modos de incluir os sujeitos no contexto educativo. Como desdobramento desta ação, a inclusão de todos os alunos nas aulas de Educação Física também é vista como um modo de: evitar o Bullying escolar, repensar questões de gênero, resolver os problemas disciplinares, diminuir o risco social, evitar o acometimento de doenças degenerativas, prevenir o uso de drogas, primar pela não discriminação dos sujeitos, descobrir novos talentos etc. Dentro desse âmbito, posso dizer que tenho percebido as práticas corporais como parte das políticas de inclusão que posicionam, forjam e constituem os diversos sujeitos envolvidos com esses processos.

Por outro lado, nota-se também que essa busca pela inclusão de todos os alunos nas aulas de Educação Física tenta marcar que todos possuem um ponto em comum e, por isso podem estar juntos, incluídos. Ora, se somos diferença, a tentativa de afirmar que todos são capazes de permanecer juntos não pode ser uma busca pelo apagamento das diferenças e um retorno ao ideal moderno de homogeneizar os sujeitos? A educação que buscamos é a da invisibilidade dos sujeitos? Como questiona Gallo (2009, p. 7): "Vivemos a diferença, ou ela está apenas em nossos discursos? [...] A diferença está aí... E não está para ser reconhecida, respeitada, tolerada. Tudo isso significa apagar a diferença, não vê-la e vivê-la".

Após essas primeiras palavras, posso dizer que a intenção deste trabalho é a de movimentar o pensamento sobre outras formas de olhar para as políticas de inclusão, numa 
tentativa de pensar sobre o que estamos produzindo e realizando em nossas escolas, em especial nas aulas de Educação Física, a partir da análise do que preveem os documentos que hoje regulam a educação inclusiva e a Educação Física escolar. Para além de considerar que as políticas inclusivas são essencialmente benevolentes, salvadoras da educação e capazes de resolver os problemas das minorias, procuro enfatizar o que os documentos oficiais nos dizem e refletir sobre a forma como, muitas vezes, são interpretados no cotidiano escolar. A opção de análise é pela inspiração genealógica (FOUCAULT, 2005) pautada nos Estudos Foucaultianos, destacando também uma análise dos discursos presentes nos documentos oficiais que hoje regulam a Educação Física e as políticas inclusivas dentro da escola e fazendo o uso dos conceitos, ferramentas de normação, normatização e normalização:

A genealogia seria, pois, relativamente ao projeto de uma inserção dos saberes na hierarquia do poder próprio da ciência, uma espécie de empreendimento para dessujeitar os saberes históricos e torná-los livres, isto é, capazes de oposição e de luta contra a coerção de um discurso teórico unitário, formal e científico. A reativação dos saberes locais - "menores", talvez dissesse Deleuze - contra a hierarquização científica do conhecimento e seus efeitos de poder intrínsecos, esse é o projeto dessas genealogias em desordem e picadinhas (FOUCAULT, 2005, p. 15-16).

Para Veiga-Neto e Lopes (2010), uma pesquisa de inspiração genealógica "não nega os objetos estudados; ela 'apenas' revela o que eles tiveram e têm de contingentes, bem como a serviço do que eles foram inventados ou a serviço do que eles se colocaram depois de inventados" (VEIGA-NETO; LOPES, 2010, p. 158). Veiga-Neto (2007, p. 59), também aponta que não há uma orientação sobre como executar uma pesquisa genealógica, mas, podemos entender a genealogia como "um conjunto de procedimentos úteis não só para conhecer o passado, como também, e muitas vezes principalmente, para nos rebelarmos contra o presente". Nesse âmbito centra-se o objetivo e os caminhos investigativos deste artigo.

Para melhor organizar minhas considerações, o texto que segue possui três seções. A primeira delas retoma o modo como diferentes racionalidades trataram aqueles considerados loucos/deficientes/anormais, articulando com os conceitos de normação, normatização e normalização, enfatizando uma gestão de riscos. A seção seguinte aborda e analisa os discursos presentes nos documentos que regulamentam e regulam a escola, as políticas de inclusão e a Educação Física na Contemporaneidade, os quais, de certo modo, reforçam a racionalidade vigente. Finalizo este artigo pensando sobre como podemos exercer a docência em Educação Física dentro das escolas de um modo que nos possibilite, para além de gerir riscos, enfatizar o ensino e outro modo de viver a diferença.

\section{Processos de normalização e gestão de riscos na escola}

Foucault (2001) apud Avelino (2011, p. 32), entendia como racionalidades "os conjuntos de prescrições calculadas e razoáveis que organizam instituições, distribuem espaços e regulamentam comportamentos; nesse sentido as racionalidades induzem uma série de efeitos sobre o real". De acordo com Castro-Gomez (2010), para Foucault, o conceito de racionalidade é utilizado para se referir ao funcionamento histórico de práticas que se inserem em relações de poder. Nessa esteira de pensamento, entendo racionalidade como uma organização que nos conduz no social, no econômico, nas instituições, dando sentido, produzindo e sendo produtora de nossas práticas. No decorrer dos tempos, diferentes racionalidades embasaram o tratamento dispensado às pessoas com deficiência. Aqui, não se trata de retomar esse processo histórico, mas de relacionar alguns pontos que possibilitam articular esse movimento aos conceitos de normatização, normação e normalização, utilizados neste trabalho, conectando-os as diferentes racionalidades.

Práxis Educativa, Ponta Grossa, v. 12, n. 2, p. 430-447, maio/ago. 2017 Disponível em: <http://www.revistas2.uepg.br/index.php/praxiseducativa > 
Entre os séculos XVI, XVII e XVIII na Europa, na mudança de ênfase de uma sociedade fundamentada na soberania, para uma sociedade com ênfase no disciplinamento dos corpos e, em seguida, para uma sociedade baseada na segurança, temos racionalidades distintas que, dentre outras características, trazem à tona um conceito de norma - importante para entender a fabricação de diferenças e as políticas de inclusão exercidas na Contemporaneidade. No curso Segurança, Território, População (1978), ministrado no Collège de France, Foucault (2008b) mostra como emergiu a Razão de Estado no século XVI, a partir da crise do pastorado e com a união do poder político com o poder pastoral que, dentre outras coisas, é condição de possibilidade para o surgimento de um modelo de Sociedade Disciplinar (século XVI-XVII), pois, mais do que administrar os indivíduos, é preciso administrar no detalhe, dominar. Numa sociedade em que a racionalidade era baseada num modelo disciplinar (FOUCAULT, 2007), as diversas instituições de sequestro buscavam atingir cada indivíduo a partir de uma norma, de um princípio de comparação. $\mathrm{Na}$ normalização disciplinar, o modelo é instituído primeiro e a norma vem depois, assim "a operação de normalização disciplinar consiste em procurar tornar as pessoas, os gestos, os atos, conformes a esse modelo, sendo normal, precisamente, quem é capaz de se conformar a essa norma e anormal quem não é capaz" (FOUCAULT, 2008b, p. 75). O poder político assume a tarefa de gerir a vida. Esse exercício do poder político sobre a vida, chamado de biopoder (poder sobre a vida), desenvolve-se a partir do século XVII em duas formas: uma anátomo-política do corpo e uma biopolítica da população.

Conexa com esses processos, nasce a Estatística como uma ciência de governo: "a Estatística que havia funcionado até então no interior dos marcos administrativos, [...] descobre e mostra, pouco a pouco que a população tem suas regularidades próprias: seus números de mortos, seu número de doentes, suas regularidades de acidentes" (FOUCAULT, 2008b, p. 138). Em meados do século XVIII, as campanhas sobre mortalidade, casamento, vacinação, entre outras, passam a ser racionalizadas para atingir a família e a população passa a ser entendida como fim: "sujeito de necessidades, de aspirações, mas também objeto nas mãos do governo" (FOUCAULT, 2008b, p. 140). Assim, com o desbloqueio das artes de governar, com o advento da população como fim do Governo e a ressignificação da Estatística como ciência de Estado, temos os mecanismos de segurança que passam a se relacionar com um modo de exercer o poder que considera centralmente a população e o homem-espécie - a biopolítica. Os mecanismos desse exercício do poder, aliados aos mecanismos disciplinares, constituem dispositivos de segurança e passam a gerir a população, utilizando-se da contagem dos nascimentos e óbitos, do controle da escassez alimentar, das campanhas de vacinação etc. (FOUCAULT, 2008b).

Nessa configuração, temos o aparecimento de noções novas para os termos caso, risco, perigo, crise - pelo menos em seu campo de atuação e nas técnicas requeridas -, pois surge uma série de formas de intervenção que consistem em "levar em conta o conjunto de descontinuidades, sem ruptura, dos doentes e não-doentes, isto é, em outras palavras, a população, e em ver nessa população [...] o que é normalmente esperado, em matéria de acometimento de doença, em matéria de morte ligada à doença" (FOUCAULT, 2008b, p. 81). No entendimento da população como fim, analisando suas descontinuidades - seu aspecto numerável, - é possível pensar na centralidade que a noção de risco toma para os mecanismos de segurança e, a partir dessa compreensão, institui-se outro modo de normalização. Após a produção das estatísticas, são pensados os riscos e elaboradas estratégias que atuem como precaução. Desse modo, além de saber o que é normalmente esperado, também se procura "reduzir as normalidades mais desfavoráveis, mais desviantes em relação à curva normal geral, reduzi-las a essa curva normal, geral" (FOUCAULT, 2008b, p. 82). Nota-se uma preocupação com os desviantes, com aqueles que não fazem parte da faixa de normalidade, com os marginalizados, os quais também são alvo dos mecanismos de segurança e podem significar um risco. 
Temos, portanto, um sistema que é, creio, exatamente o inverso do que podíamos observar a propósito das disciplinas. Nas disciplinas partia-se de uma norma e era em relação ao adestramento efetuado pela norma que era possível distinguir, depois, o normal do anormal. Aqui, ao contrário, vamos ter uma identificação do normal e do anormal, vamos ter uma identificação das diferentes curvas de normalidade, e a operação de normalização vai consistir em fazer essas diferentes distribuições de normalidade funcionarem umas em relação às outras e [em] fazer de sorte que as mais desfavoráveis sejam trazidas às que são mais favoráveis. [...] Logo, eu diria que não se trata mais de uma normação, mas sim, no sentido estrito, de uma normalização (FOUCAULT, 2008b, p. 82-83, grifos meus).

Ao pensar sobre esses diferentes movimentos que constituíram certas racionalidades, pode-se dizer que a partir dos dispositivos disciplinares, existe um processo de normação, em que a norma é posicionada em primeiro e, depois, os indivíduos são comparados em relação àquela norma e designados como normais ou anormais. Com os dispositivos de segurança, a norma age num processo de normalização em que a definição de quem é normal ou anormal acontece por meio das regularidades. Lopes e Fabris (2013) lembram que as operações da norma agenciadas por dispositivos disciplinares ou de seguridade não são excludentes e normalizar seria uma ação de dobradiça de práticas disciplinares e de regulação sobre os sujeitos. Além disso, para as autoras "a normalidade (média) somada à noção de inclusão como imperativo de Estado, agem contando com outro tipo de operação, a normatização” (LOPES; FABRIS, 2013, p. 44, grifo meu).

Importa destacar que, na organização social contemporânea, vimos esses processos como organizadores de uma racionalidade que procura incluir a todos nas normas neoliberais vigentes. Para Lopes (2009), a inclusão, via políticas de inclusão escolares, sociais, assistenciais e de trabalho, funciona como um dispositivo biopolítico a serviço da segurança das populações. Ao estarem incluídas nos grupos, nos registros oficiais, no mercado de trabalho, nas cotas de bolsaassistência, na escola etc., as pessoas tornam-se alvos fáceis das ações do Estado. Trata-se de ações que visam a conduzir as condutas humanas dentro de um jogo com regras definidas, no interior dos distintos e dos muitos grupos sociais. Tais regras não engessam as relações, nem mesmo as variadas participações da população e dos indivíduos em cada ação em que se mobiliza ou é mobilizada. Ademais, todos os indivíduos são alvo dessas políticas, pois há a proliferação de verdades que apontam para que todos se curvem ao imperativo da inclusão. O Estado "se fortalece operando como um mediador social que articula e cria estratégias capazes de gerir a vida de cada indivíduo e do coletivo da população" (LOPES; FABRIS, 2013, p. 30).

Se olharmos para o modo como a escola e as políticas de inclusão se enredam nesses processos, é preciso retomar a invenção e o propósito de algumas instituições no tratamento dispensado aos sujeitos - que, seja por um processo de normação ou por um processo de normalização, foram classificados como anormais, fora de um padrão ou fora da média e precisavam ser incluídos - como um modo, dentre outros aspectos, de gerenciar riscos. Segundo Lopes e Fabris (2013), no final da Idade Média, os "reconhecidos como anormais ganham direito à vida, porque são reconhecidos pela Igreja como criaturas de Deus" (LOPES; FABRIS, 2013, p. 47). A anormalidade deixa de ser excluída e passa a ser segregada, tratada nas instituições de confinamento. Com o advento das práticas disciplinares é possível perceber que as chamadas instituições de sequestro - o asilo psiquiátrico, a penitenciária, a casa de correção, o estabelecimento de educação vigiada, os hospitais etc. - funcionam, por meio da divisão binária, marcando: louco/não louco; perigoso/inofensivo; normal/anormal. São lugares que se ocupam de técnicas que procuram medir, controlar e corrigir (FOUCAULT, 2007). Cada uma delas, portanto, tinha em seu propósito conhecer os sujeitos para controlá-los, educá-los para serem dóceis e, se necessário, corrigi-los em operações que faziam parte de uma lógica disciplinar de condução das condutas, de governo.

Práxis Educativa, Ponta Grossa, v. 12, n. 2, p. 430-447, maio/ago. 2017 Disponível em: <http://www.revistas2.uepg.br/index.php/praxiseducativa > 
Esses lugares, enquanto exerciam um efeito de normação sobre os sujeitos, também conheciam e governavam a cada um. Com a definição de uma norma a priori e pelo conjunto observável da população, instituem-se o normal e o anormal e, para que se pudesse viver dentro da racionalidade disciplinar da Modernidade na Europa, foi preciso "criar instituições capazes de educar os recém-chegados [...] bem como aqueles considerados anormais" (LOPES; FABRIS, p. 50). Nesse caso, "a escola foi a que mais se mostrou produtiva na vigilância e no controle dos indivíduos" (ibidem, p. 50). Com isso, não se retira o papel de outras instituições, mas se realça a importância da instituição escolar para a conformação de um tipo de sociedade, de uma determinada racionalidade. Tais arranjos perpetuam-se até os dias de hoje, em que a escola ainda é considerada uma das principais produtoras de subjetividades (VEIGA-NETO, 2006). No entendimento da inclusão como um imperativo de Estado, podemos pensar que a escola é hoje um locus privilegiado para que práticas dessa lógica se estabeleçam como verdades que não estavam sempre presentes, mas que foram se instituindo e tomando força.

Para um olhar mais específico sobre a organização da escola na função de educar os considerados anormais, podemos pensar no exemplo de como o Brasil começou a institucionalizar os indivíduos que tinham algum tipo de deficiência. No século XIX surgiram as primeiras instituições destinadas ao tratamento das pessoas com deficiência no Brasil. Especificamente, no ano de 1854 temos o advento do chamado Instituto Imperial dos Meninos Cegos, hoje conhecido Instituto Benjamin Constant. Já em 1857 temos o Instituto dos Surdos Mudos, hoje Instituto Nacional da Educação de Surdos. Além desses, para outras deficiências tivemos em 1924 a fundação do Instituto Pestalozzi, atendendo pessoas com deficiência mental. A Associação de Assistência à Criança Defeituosa (AACD) em 1952 e a Associação de Pais e Amigos dos Excepcionais no ano de 1954 (MACHADO, 2010).

Nesses casos, ainda que os indivíduos tivessem um atendimento educacional, eles não frequentavam escolas regulares ou as chamadas classes especiais, que foram surgir depois desse período, em meados da década de 60. A lógica inclusiva, no modo como é entendida hoje, ainda não existia. Todavia, do mesmo modo, era necessário conhecer e produzir saberes sobre tais pessoas para melhor conduzi-las e governá-las. A escola tornou-se central no conhecimento desses sujeitos que, por diversos processos de exclusão, estavam à margem e foram sendo incorporados pela sociedade e posicionados em um determinado lugar.

Ao analisarmos as práticas sobre os sujeitos considerados anormais, de risco, percebe-se que elas estão em constante deslocamento. Hoje, por exemplo, ao colocarmos um aluno com deficiência numa escola regular, sabemos que a lógica da exclusão, do enclausuramento, da reclusão e da integração se transformou. As relações entre inclusão e neoliberalismo, possibilitam, entre outras coisas, conhecer cada vez mais os indivíduos, posicioná-los no jogo e ampliar sua participação e produtividade, atuando como um modo de gerenciar esses que estão à margem, mas sem deixá-los enclausurados ou segregados dos demais - ao mesmo tempo, ainda é preciso destacar que, dentro de operações de inclusão, também existem operações que excluem.

Cada racionalidade, que constituímos e por meio das quais somos constituídos, é atravessada, de certo modo, por um conjunto de estratégias e práticas que são constantemente mobilizadas. Ao percebermo-nos imersos numa sociedade que deseja incluir a todos, entende-se que outros modos de condução sejam acionados para dar conta dessa nova ordem. Conectado a isso está o incentivo para que o sujeito seja autorregulado, responsável por si e que internalize características que o mantenham em movimento, no jogo. Ao pensar nas práticas dos professores de Educação Física, vejo esse processo acontecendo. A implantação de ações que visam, na escola, mediante o esporte ou uma educação em tempo integral, a gerenciar crianças e jovens considerados marginalizados e a diminuir os riscos, são feitos afinados à lógica vigente. A

Práxis Educativa, Ponta Grossa, v. 12, n. 2, p. 430-447, maio/ago. 2017 Disponível em: <http://www.revistas2.uepg.br/index.php/praxiseducativa > 
inclusão de alunos com deficiência na escola regular é outro dos exemplos dessa racionalidade neoliberal que, dentre outros aspectos, coloca todos no jogo.

Dentro desse aspecto da lógica inclusiva, que busca incluir os sujeitos na escola como algo puramente benevolente, problematizo se essa inclusão abarca os processos de ensino e aprendizagem necessários a cada particularidade do educando ou se detém à operações que trazem o sujeito para o social, considerando que, a partir disso, não estão mais à margem, em risco. Na próxima seção, por meio da análise dos documentos, destaco o que a legislação traz sobre isso.

\section{Sobre a Educação física e as políticas de inclusão}

Ao olharmos para cada racionalidade e as condições de possibilidade que permitiram seus agenciamentos, é preciso que não deixemos escapar um dos modos que legitima cada racionalidade, principalmente numa sociedade como a nossa, baseada num aparato jurídico. Assim, para problematizarmos os enredos contemporâneos que regulamentam e regulam a Educação Física na escola, bem como para as políticas inclusivas que se estabelecem como práticas e o papel que a Educação Física vem cumprindo nos entremeios das políticas inclusivas é necessária uma mirada para os documentos que as compõem. Não é o caso de retomar todos os documentos que estabelecem as presenças e as obrigatoriedades da Educação Física e das políticas inclusivas, mas de analisar o contexto atual. Do mesmo modo, não será preciso tratar todo o conteúdo de cada documento selecionado, mas o destaque de algumas recorrências discursivas que permitem refletir sobre os atravessamentos entre as políticas inclusivas e a Educação Física escolar.

São tratados nesta pesquisa os seguintes documentos: LDB 9394/96 (BRASIL, 1996); Parâmetros Curriculares Nacionais (BRASIL, 1997); Política Nacional de Educação Especial na perspectiva da Educação Inclusiva (BRASIL, 2008); Resolução no 05, de 17 de dezembro de 2009 - Fixa as Diretrizes Nacionais para a Educação Infantil (BRASIL, 2009); Resolução no 07, de 14 de dezembro de 2010 - Fixa as Diretrizes Nacionais para o Ensino Fundamental de 9 (nove) anos (BRASIL, 2010); Resolução n ${ }^{\circ}$ 02, de 30 de janeiro de 2012 - Fixa as Diretrizes Nacionais para o Ensino Médio (BRASIL, 2012) e Diretrizes Curriculares Nacionais, de 2013 (BRASIL, 2013a). Além destes, como ilustrativos de práticas que adentram o contexto escolar e se relacionam com políticas inclusivas e com a Educação Física destacam-se os objetivos e finalidades do Programa Segundo Tempo, do Ministério do Esporte (BRASIL, 2003); do Programa Atleta na Escola, estabelecido pelo Ministério do Esporte e da Educação (BRASIL, 2013b) e do Programa Esporte na Escola, do Ministério do Esporte e Ministério da Educação (BRASIL, 2013c).

Nos dias de hoje, um basilar da educação brasileira atual é a Lei de Diretrizes e Bases da Educação Nacional, promulgada em 1996, a nossa conhecida LDB 9394/96. Nela encontramos os principais marcos sobre a Educação Física escolar, bem como os primeiros indícios do que se trataria uma educação inclusiva. Em recente atualização, encontramos no artigo 26 da referida lei a regulação da Educação Física e nos artigos 58 e 59 as especificidades do título educação especial, que já estabelece uma educação inclusiva.

Art. 26. [...] $3^{\circ}$ A educação física, integrada à proposta pedagógica da escola, é componente curricular obrigatório da educação básica, sendo sua prática facultativa ao aluno: I - que cumpra jornada de trabalho igual ou superior a seis horas; II - maior de trinta anos de idade; III - que estiver prestando serviço militar inicial ou que, em situação similar, estiver obrigado à prática da educação física; IV - amparado pelo Decreto-Lei n ${ }^{\circ}$ 1.044, de 21 de outubro de 1969; V - (vetado); VI - que tenha prole.

Práxis Educativa, Ponta Grossa, v. 12, n. 2, p. 430-447, maio/ago. 2017 Disponível em: <http://www.revistas2.uepg.br/index.php/praxiseducativa $>$ 
Art. 58. Entende-se por educação especial, para os efeitos desta Lei, a modalidade de educação escolar oferecida preferencialmente na rede regular de ensino, para educandos com deficiência, transtornos globais do desenvolvimento e altas habilidades ou superdotação. (Redação dada pela Lei no 12.796, de 2013).

Art. 59. Os sistemas de ensino assegurarão aos educandos com deficiência, transtornos globais do desenvolvimento e altas habilidades ou superdotação: (Redação dada pela Lei n ${ }^{\circ}$ 12.796, de 2013).

I - curriculos, métodos, técnicas, recursos educativos e organização especificos, para atender as suas necessidades; II - terminalidade específica para aqueles que não puderem atingir o nível exigido para a conclusão do ensino fundamental, em virtude de suas deficiências, e aceleração para concluir em menor tempo o programa escolar para os superdotados; III - professores com especialização adequada em nível médio ou superior, para atendimento especializado, bem como professores do ensino regular capacitados para a integração desses educandos nas classes comuns; IV - educação especial para o trabalho, visando a sua efetiva integração na vida em sociedade, inclusive condições adequadas para os que não revelarem capacidade de inserção no trabalho competitivo, mediante articulação com os órgãos oficiais afins, bem como para aqueles que apresentam uma habilidade superior nas áreas artística, intelectual ou psicomotora; V acesso igualitário aos benefícios dos programas sociais suplementares disponíveis para o respectivo nível do ensino regular (BRASIL, 1996).

A análise da LDB 9394/96, em especial dos artigos supracitados, evidencia uma Educação Física obrigatória na escola, mas ainda não para todos os alunos. Pautada num modelo que a percebe como possível de ser facultada, a Educação Física, de certo modo, é posta à margem do currículo, pois parece não ser importante para todos. Os incisos I até V do artigo 26, parágrafo $3^{\circ}$, deixam claro que para alguns sujeitos a Educação Física não é relevante e pode ser dispensada de seus currículos. Quando olhamos para os artigos que regulam a escolarização de educandos com deficiência, transtornos globais do desenvolvimento e altas habilidades ou superdotação, percebe-se a convocação para uma educação inclusiva nas escolas regulares. Além disso, há a previsão de mudanças nos currículos com as ideias de adaptações e de terminalidade específica.

$\mathrm{Na}$ esteira de pensamento de Foucault (1995) entendendo, segundo o autor, que nem tudo é ruim, mas tudo é perigoso, problematizo a questão curricular que já se destaca nesses artigos analisados. De um lado temos a Educação Física facultada a alguns alunos e, portanto, podendo ser considerada uma disciplina de menos valor e, de outro lado, a educação para educandos com deficiência sendo pautada por adaptações curriculares. Embora saibamos da importância e da validade de se considerar uma flexibilidade curricular de acordo com as necessidades de cada educando, também é possível problematizar que as adaptações curriculares podem constituir o apagamento de muitos aspectos necessários e relevantes para cada educando. Além disso, ao olharmos para a Educação Física para educandos com deficiência, podemos refletir que, por a Educação Física ser vista como dispensável para alguns e pelos currículos preverem adaptações para alunos com deficiência, talvez a união de ambos - na Educação Física para educandos com deficiência - possa ser vista como algo de menor importância nas escolas. Nessa perspectiva, podemos ter alunos não participantes das aulas ou atuando como um mero colaborador ou, até mesmo, fazendo atividades de outras disciplinas enquanto deveriam estar nas aulas de Educação Física.

Nos Parâmetros Curriculares Nacionais, postos em cena a partir de 1997, vemos o papel destinado à Educação Física para aqueles considerados, no documento, como portadores de necessidades especiais. Para exemplificar, trago excertos dos PCN's (BRASIL, 1997) que foram elaborados para Educação Física no $3^{\circ}$ e $4^{\circ}$ ciclos do Ensino Fundamental.

Por desconhecimento, receio ou mesmo preconceito, a maioria dos portadores de necessidades especiais tendem a ser excluídos das aulas de Educação Física. A

Práxis Educativa, Ponta Grossa, v. 12, n. 2, p. 430-447, maio/ago. 2017 Disponível em: <http://www.revistas2.uepg.br/index.php/praxiseducativa $>$ 
participação nessa aula pode trazer muitos benefícios a essas crianças, particularmente no que diz. respeito ao desenvolvimento das capacidades perceptivas, afetivas, de integração e inserção social, que levam este aluno a uma maior condição de consciência, em busca da sua futura independência. É fundamental, entretanto, que alguns cuidados sejam tomados. Em primeiro lugar, deve-se analisar o tipo de necessidade especial que esse aluno tem, pois existem diferentes tipos e graus de limitações, que requerem procedimentos específicos. Embora existam inúmeros cursos de aprofundamento, de especialização, de mestrado e mesmo de doutorado no país, que preparam professores de Educação Física para a atuação na área de educação motora adaptada, nos contextos em que não houver professores preparados para atuar com este tipo de população é necessário que haja orientação médica e, em alguns casos, a supervisão de um especialista em fisioterapia, um neurologista, psicomotricista ou psicólogo, pois as restrições de movimentos, posturas e esforço podem implicar graves riscos. Garantidas as condições de segurança, o professor deve fazer adaptações, criar situações de modo a possibilitar a participação dos alunos especiais. Esse aluno poderá participar dos jogos ou danças, por exemplo, criando-se um papel específico para sua atuação, onde cada limitação gerará um nível de solução, pois o desenvolvimento da percepção das possibilidades permite a sua consequente potencialização. O professor deve ser flexível, fazendo as adequações necessárias no plano gestual, nas regras das atividades, na utilização de materiais e do espaço para estimular, tanto no aluno portador de necessidades especiais como no grupo, todas as possibilidades que favoreçam o princípio da inclusão. Caminham, também nesta direção, a informação e a discussão sobre a participação de portadores de necessidades especiais em competições oficiais, adaptadas para cada condição específica, em que se pode valorizar a superação de limitações e impedimentos. Outro ponto importante é em relação a situações de vergonha e exposição nas aulas de Educação Física. A maioria das pessoas portadoras de deficiências tem traços fisionômicos, alterações morfológicas ou problemas de coordenação que as destacam das demais. Uma atitude positiva de todos diante dessas diferenças é algo que se construirá na convivência e que dependerá muito da postura pedagógica que o professor adotar concretamente nesta direção. A aula de Educação Física deve favorecer a construção de uma atitude digna e de respeito próprio por parte do portador de necessidades especiais, $e$ a convivência com ele pode possibilitar a construção de atitudes de solidariedade, respeito e aceitação, sem preconceitos (BRASIL, 1997, p. 56-57, grifos meus).

Com os PCN's sendo distribuídos a escolas públicas na década de 90, pode-se considerar que os princípios neles contidos chegaram a diferentes espaços escolares deste país. No texto em destaque e, em especial, nas passagens grifadas, é possível pensarmos no papel destinado para a Educação Física dos educandos com deficiência. Quando se fala nos benefícios e nas funções da Educação Física nesse contexto, os discursos indicam que sua função é a de trabalhar capacidades que envolvam percepção, afetividade, integração e inserção social do educando com deficiência. Além disso, nota-se uma busca para que essas aulas desenvolvam o respeito, a solidariedade e o convívio entre os colegas da turma. Ao aluno com deficiência cabe se respeitar e ter uma atitude digna. Há um foco nas questões morais e de condução social, cujo trato é bastante diverso do aplicado ao pensamento de ensino destinado aos demais colegas. Embora se acredite na importância de um trabalho atitudinal em todas as disciplinas escolares, parece que o centro do processo de trabalhos dos educandos com deficiência, nesse documento, é restrito ao atitudinal. Aspectos conceituais não são mencionados e os procedimentais, na passagem acima, acabam suplicando por um cuidado nas aulas, traduzindo a Educação Física como algo perigoso a alguns alunos.

Nessa forma de colocar a Educação Física, o documento a destaca como alguma coisa que pode implicar graves riscos para os educandos. Ressalta-se, ainda, o dever da supervisão pelos ditos especialistas: fisioterapeutas, neurologistas, psicomotricistas, psicólogos etc.- na ausência dos professores considerados preparados - sobre os outros professores que se aventurarem nas aulas para alunos com deficiência. Essa perspectiva, além de reforçar que a deficiência precisa de supervisão médica, está centralizada num modelo médico da deficiência, mostrando limitações e não as possibilidades dos sujeitos. Ademais, a Educação Física, de acordo

Práxis Educativa, Ponta Grossa, v. 12, n. 2, p. 430-447, maio/ago. 2017 Disponível em: <http://www.revistas2.uepg.br/index.php/praxiseducativa > 
com os PCNs, pode causar vergonha aos alunos. Cabe destacar que, apesar de os PCNs não terem sido adotados por todos os professores brasileiros, essa era a concepção de sujeito com deficiência expressa pelo documento.

É preciso problematizar, nesses recortes, o papel a que a Educação Física para alunos com deficiência estava designada: útil para a integração, para a afetividade e para a inserção dos sujeitos e focada nas questões atitudinais. Tais prerrogativas conduzem a pensar o quanto essa disciplina, durante os planejamentos curriculares nas escolas, pode ter sido vista apenas com objetivos de ordem moral. Ou seja, aquilo que legitima uma área no espaço escolar, a questão dos saberes e do ensino, não é expressa no documento. Todos esses fatores colaboram para colocar a Educação Física dos educandos com deficiência como algo que está mais para o social, para a normalização dos sujeitos, para o gerenciamento dos riscos (LOPES; FABRIS, 2013) do que para o ensino.

Após a análise desses documentos que surgem na década de 90 e, em alguma medida, já procuram incorporar a discussão de uma educação inclusiva iniciada nessa época, passo a focar nos documentos que vem à tona após a publicação da Política Nacional de Educação Especial na Perspectiva da Educação Inclusiva (BRASIL, 2008). A começar, trato dessa política destacando seus objetivos:

\begin{abstract}
Assegurar a inclusão escolar de alunos com deficiência, transtornos globais do desenvolvimento e altas habilidades/superdotação, orientando os sistemas de ensino para garantir: acesso ao ensino regular, com participação, aprendizagem e continuidade nos níveis mais elevados do ensino; transversalidade da modalidade de educação especial, desde a educação infantil até a educação superior; oferta do atendimento educacional especializado; formação de professores para o atendimento educacional especializado e demais profissionais da educação para a inclusão; participação da família e da comunidade; acessibilidade arquitetônica, nos transportes, nos mobiliários, nas comunicações e informação; e articulação intersetorial na implementação das políticas públicas (BRASIL, 2008).
\end{abstract}

Essa política marca uma perspectiva que torna legítima e irrevogável a educação inclusiva no Brasil. Reforça que os sistemas de ensino devem garantir o acesso às escolas regulares e fala em continuidade nos diferentes níveis de ensino. Também aborda a formação de professores, a acessibilidade e uma ação de responsabilização de todos os setores para que essa inclusão aconteça. O documento analisado não traz uma parte específica para a Educação Física ou sobre o que deve ser trabalhado com os alunos nas escolas regulares. Todavia, expressa a necessidade de que os educandos com deficiência que ingressem nas escolas regulares sejam atendidos nas salas de Atendimento Educacional Especializado (AEE). A respeito dessas salas é dito que o foco do trabalho de apoio para a inserção dos alunos nas classes regulares dar-se-á pelo "ensino de linguagens e códigos específicos de comunicação e sinalização e tecnologia assistiva" (BRASIL, 2008, p. 10). Não há referência sobre questões que envolvam as práticas corporais, por exemplo. $\mathrm{Na}$ Educação Infantil, o documento, ao falar desse atendimento especializado afirma que "o lúdico, o acesso às formas diferenciadas de comunicação, a riqueza de estímulos nos aspectos físicos, emocionais, cognitivos, psicomotores e sociais e a convivência com as diferenças favorecem as relações interpessoais, o respeito e a valorização da criança" (BRASIL, 2008, p. 10). Para essa etapa, outros aspectos são citados para o atendimento especializado, embora o foco seja para favorecer o convívio social e as questões de cunho moral ou civilizador. Veiga-Neto (2003) afirma que a escola é uma "instituição envolvida na civilidade, ou seja, na transformação dos homens: de selvagens em civilizados" (VEIGA-NETO 2003, p. 104). Esse é um dos aspectos que fez da escola "a principal encarregada de construir um tipo de mundo que chamamos de mundo moderno" (VEIGA-NETO, 2003, p. 104). Ao analisarmos esse foco nas questões morais, quando se trata de uma educação inclusiva, podemos refletir que,

Práxis Educativa, Ponta Grossa, v. 12, n. 2, p. 430-447, maio/ago. 2017 Disponível em: <http://www.revistas2.uepg.br/index.php/praxiseducativa > 
ao trazer esses sujeitos para a escola e centrarmos os trabalhos nesses processos, mais do que incluir esses sujeitos, estamos os in/excluindo (LOPES, 2009).

Após o olhar para os objetivos da Política Nacional de Educação Especial na perspectiva da Educação Inclusiva, avanço para um exame das Diretrizes Curriculares Nacionais por meio das resoluções que estabeleceram as diretrizes da Educação Infantil (BRASIL, 2009), do Ensino Fundamental (BRASIL, 2010) e do Ensino Médio (BRASIL, 2012). Ao analisar a especificidade de cada modalidade de ensino, destacam-se em seus discursos, aspectos semelhantes aos já abordados aqui. Para ampliar a conversa, foram avultados alguns artigos dessas resoluções que tratam de aspectos relacionados à Educação Física e ao trabalho para educandos com deficiência.

Art. $8^{\circ}$ A proposta pedagógica das instituições de Educação Infantil deve ter como objetivo garantir à criança acesso a processos de apropriação, renovação e articulação de conhecimentos e aprendizagens de diferentes linguagens, assim como o direito à proteção, à saúde, à liberdade, à confiança, ao respeito, à dignidade, à brincadeira, à convivência e à interação com outras crianças.

$\int 1^{\circ} \mathrm{Na}$ efetivação desse objetivo, as propostas pedagógicas das instituições de Educação Infantil deverão prever condições para o trabalho coletivo e para a organização de materiais, espaços e tempos que assegurem: VII - a acessibilidade de espaços, materiais, objetos, brinquedos e instruções para as crianças com deficiência, transtornos globais de desenvolvimento e altas habilidades/superdotação.

Art. $9^{\circ}$ As práticas pedagógicas que compõem a proposta curricular da Educação Infantil devem ter como eixos norteadores as interações e a brincadeira, garantindo experiências que: I - promovam o conhecimento de si e do mundo por meio da ampliação de experiências sensoriais, expressivas, corporais que possibilitem movimentação ampla, expressão da individualidade e respeito pelos ritmos e desejos da criança (BRASIL, 2009, grifos meus).

$[\cdots]$

Art. 14 O currículo da base nacional comum do Ensino Fundamental deve abranger, obrigatoriamente, conforme o art. 26 da Lei $n^{\circ}$ 9.394/96, o estudo da Língua Portuguesa e da Matemática, o conhecimento do mundo físico e natural e da realidade social e política, especialmente a do Brasil, bem como o ensino da Arte, a Educação Física e o Ensino Religioso.

$\int 5^{\circ}$ A Educação Física, componente obrigatório do currículo do Ensino Fundamental, integra a proposta político-pedagógica da escola e será facultativa ao aluno apenas nas circunstâncias previstas no $\int 3^{\circ}$ do art. 26 da Lei no $9.394 / 96$.

\section{$[\ldots]$}

Art. 30 Os três anos iniciais do Ensino Fundamental devem assegurar: I - a alfabetização e o letramento; II - o desenvolvimento das diversas formas de expressão, incluindo o aprendizado da Língua Portuguesa, a Literatura, a Música e demais artes, a Educação Física, assim como o aprendizado da Matemática, da Ciência, da História e da Geografia.

Art. 31 Do $1^{\circ}$ ao $5^{\circ}$ ano do Ensino Fundamental, os componentes curriculares Educação Física e Arte poderão estar a cargo do professor de referência da turma, aquele com o qual os alunos permanecem a maior parte do período escolar, ou de professores licenciados nos respectivos componentes.

$[\ldots]$

Art. 41 O projeto político-pedagógico da escola e o regimento escolar, amparados na legislação vigente, deverão contemplar a melhoria das condições de acesso e de permanência dos alunos com deficiência, transtornos globais do desenvolvimento e altas habilidades nas classes comuns do

Práxis Educativa, Ponta Grossa, v. 12, n. 2, p. 430-447, maio/ago. 2017 Disponível em: <http://www.revistas2.uepg.br/index.php/praxiseducativa $>$ 
ensino regular, intensificando o processo de inclusão nas escolas públicas e privadas e buscando a universalização do atendimento. Parágrafo único. Os recursos de acessibilidade são aqueles que asseguram condições de acesso ao currículo dos alunos com deficiência e mobilidade reduzida, por meio da utilização de materiais didáticos, dos espaços, mobiliários e equipamentos, dos sistemas de comunicação e informação, dos transportes e outros serviços (BRASIL, 2010, grifos meus).

$[\cdots]$

Art. $9^{\circ}$ A legislação nacional determina componentes obrigatórios que devem ser tratados em uma ou mais das áreas de conhecimento para compor o currículo:

I - são definidos pela LDB: b) a Educação Física, integrada à proposta pedagógica da instituição de ensino, sendo sua prática facultativa ao estudante nos casos previstos em Lei;

\section{$[\cdots]$}

Art. 16. O projeto político-pedagógico das unidades escolares que ofertam o Ensino Médio deve considerar: XV - valorização e promoção dos direitos humanos mediante temas relativos a gênero, identidade de gênero, raça e etnia, religião, orientação sexual, pessoas com deficiência, entre outros, bem como práticas que contribuam para a igualdade e para o enfrentamento de todas as formas de preconceito, discriminação e violência sob todas as formas (BRASIL, 2012, grifos meus).

Esses textos também estão presentes nas Diretrizes Curriculares Nacionais publicadas em 2013 (BRASIL, 2013a), mas, para não tornar a análise repetitiva, as discussões neste trabalho ficarão em torno nos excertos já mencionados. Nos destaques acima, é possível notar que as resoluções reforçam a ideia de uma Educação Física facultativa a alguns alunos e, de certo modo, com menos relevância dentro do âmbito escolar. Além disso, a resolução que trata do Ensino Fundamental, em seu artigo 31, estabelece que esse componente pode ser trabalhado por professores que não possuem formação específica na área. Sobre esses aspectos, autores (ETCHEPARE; PEREIRA; ZINN, 2003; DARIDO; RANGEL, 2008; FIORIO; LYRA, 2013) afirmam que o ensino dos conteúdos previstos para a área fica negligenciado pela falta de conhecimento dos professores que não tem graduação em Educação Física. Nas colaborações de Silva (2001) sobre a análise dos currículos, entende-se que a seleção dos saberes e dos conhecimentos considerados válidos são parte de relações de poder, no sentido em que os Estudos Foucaultianos propõem ao tema, pois as seleções e as disputas em torno do currículo estão ligadas a questões de saber-poder. Além disso, essas escolhas possuem relação com o tipo de sujeitos que desejamos formar.

Sobre os educandos com deficiência, percebe-se um foco nas questões de acessibilidade aos espaços e no acesso ao ensino regular por meio do incentivo às adaptações curriculares e à permanência desses alunos. O discurso presente nas resoluções é semelhante aos que povoam os outros documentos. Contudo, para ampliar a discussão já iniciada, ressalto que para tratar da permanência desses alunos nas escolas regulares, uma série de medidas são consideradas nos sistemas de ensino. É o caso da aprovação automática amparada pela terminalidade específica ou de um currículo enxuto pautado no incentivo às adaptações curriculares, dentre outras coisas. Para além de pensar nessas questões como boas ou ruins, proponho a reflexão sobre o que está sendo feito em nome disso. Muitas vezes, os alunos ficam à margem da escola, pelos cantos, com pouquíssima participação efetiva e produtiva para ele. Pelo simples fato de estar dentro, por ter passado por processos de normação e de normalização, têm-se a certeza de que o educando com deficiência está incluído, quando ele pode estar sendo excluído. No caso da Educação Física, não basta pensarmos que o fato de estar junto e assistindo aos colegas nas práticas corporais, afinal alguns documentos consideram a Educação Física para educandos com deficiência um risco, é uma prática inclusiva. Ao contrário, nessas ocasiões encontramos a prática insidiosa da exclusão. Como tenho tentado destacar neste trabalho, ao colocarmos os alunos para dentro instituições,

Práxis Educativa, Ponta Grossa, v. 12, n. 2, p. 430-447, maio/ago. 2017 Disponível em: <http://www.revistas2.uepg.br/index.php/praxiseducativa > 
gerenciando suas condutas e evitando riscos e, ao mesmo tempo, negligenciarmos aspectos importantes de seu ensino, estamos enfatizando a exclusão.

Além dos já citados documentos que estabelecem a Educação Física escolar e a educação inclusiva, para seguir essa problematização, abordo alguns programas do Governo Federal que enredam a Educação Física escolar e possuem uma especificidade para educandos com deficiência. São eles: programas Atleta na Escola (BRASIL, 2013b), Esporte na Escola (BRASIL, 2009) e Segundo Tempo (BRASIL, 2003). A análise desses programas centra-se nos objetivos, nas leis e nos órgãos que os colocam em circulação dentro das escolas.

O programa Atleta na Escola foi instituído no ano de 2013, em articulação entre o Ministério do Esporte e o Ministério da Educação, e tem como objetivo incentivar a prática esportiva nas escolas, democratizar o acesso ao esporte, desenvolver e difundir valores olímpicos e paralímpicos entre estudantes da Educação Básica, estimular a formação do atleta escolar e identificar e orientar jovens talentos ${ }^{2}$. Para esses propósitos, o Governo Federal buscou parcerias com os Estados, Distrito Federal, Municípios, escolas públicas e privadas, Comitês Olímpicos e Paralímpicos Brasileiros e Confederações Brasileiras de Atletismo, Judô e Voleibol. Nesse programa são apoiadas as modalidades olímpicas Judô, Voleibol e Atletismo e, na modalidade paralímpica, Atletismo, Bocha, Futebol de Cinco, Futebol de Sete, Goalball, Judô, Natação, Tênis de Mesa, Tênis em Cadeira de Rodas e Voleibol Sentado. As ações incluem jogos escolares como parte do processo de classificação para uma Etapa Nacional dos Jogos Escolares que traz visibilidade aos atletas, além do centro de iniciação esportiva, que realiza o treinamento de atletas considerados como promessa de medalhas. Aqueles tidos com potencial de conquista olímpica ou paralímpica entram no Plano Brasil Medalhas e passam a integrar o programa de bolsas esportivas (BRASIL, 2013b). É um programa destinado, inicialmente, para as escolas.

O Programa Segundo Tempo, também proposto pelos Ministérios da Educação e do Esporte, foi elaborado no ano de 2003 com a finalidade democratizar o acesso à prática e à cultura do esporte de forma a promover o desenvolvimento integral de crianças, adolescentes e jovens, como fator de formação da cidadania e melhoria da qualidade de vida, prioritariamente em áreas de vulnerabilidade social. Seus objetivos são: oferecer práticas esportivas educacionais, estimulando crianças e adolescentes a manterem uma interação efetiva que contribua para o seu desenvolvimento integral; oferecer condições adequadas para a prática esportiva educacional de qualidade; desenvolver valores sociais; contribuir para a melhoria das capacidades físicas e habilidades motoras; contribuir para a melhoria da qualidade de vida (autoestima, convívio, integração social e saúde); contribuir para a diminuição da exposição aos riscos sociais (drogas, prostituição, gravidez precoce, criminalidade, trabalho infantil) e maior conscientização da prática esportiva, assegurando o exercício da cidadania ${ }^{3}$.

No ano de 2009, o PST passou por um deslocamento. O Ministério do Esporte, partindo do entendimento de que "o caminho para a democratização do esporte é a escola" (BRASIL, 2013c), reforça a parceria com o Ministério da Educação e outros órgãos e propõe a oferta do esporte educacional integrado ao projeto pedagógico escolar, na perspectiva da educação em tempo integral. A proposta foi concretizada pela inserção do PST nas escolas participantes do programa Mais Educação. Em 2011 e 2012, essa articulação foi chamada de Programa Segundo Tempo na Escola e, em 2013, passou a chamar-se Esporte na Escola (BRASIL, 2013c).

\footnotetext{
${ }^{2}$ Disponível em: http://atletanaescola.mec.gov.br/programa.html. Acesso em 10 de agosto de 2014.

3 Disponível em: http://www.esporte.gov.br/index.php/institucional/esporte-educacao-lazer-e-inclusaosocial/segundo-tempo/objetivos. Acesso em 10 de agosto de 2014.
}

Práxis Educativa, Ponta Grossa, v. 12, n. 2, p. 430-447, maio/ago. 2017 Disponível em: <http://www.revistas2.uepg.br/index.php/praxiseducativa $>$ 
Num olhar rápido sobre esses programas, percebe-se que todos estão vinculados a outros setores e campos, e seus objetivos atravessam a escola. Além disso, o primeiro deles procura incluir o Brasil como um dos destaques dos jogos Olímpicos e Paralímpicos do Rio de Janeiro em 2016 e, pelo pagamento de bolsas, inclui os sujeitos no jogo econômico (LOPES, 2009). O Programa Segundo Tempo amplia-se em parcerias com o Ministério da Educação e traduz em seus objetivos aspectos condizentes com as ações previstas na escola. Possui um caráter inclusivo na medida em que seus principais objetivos são diminuir o risco social e incluir crianças e jovens na sociedade e no jogo econômico. O professor de Educação Física, nesse caso, trabalha desde a coordenação até a implantação e a execução dos projetos.

Percebe-se, na análise dos objetivos e finalidades desses programas, uma busca pelo gerenciamento dos alunos considerados em risco e de uma inclusão nos variados espaços, tanto no aspecto social, quanto no econômico. Os textos e objetivos dos programas, bem como dos demais documentos, evidenciam uma preocupação em como incluir o aluno, em sua acessibilidade, em fazê-lo permanecer na escola, em trabalhar aspectos civilizantes e moralizadores, no lugar de um debate sobre o conhecimento, sobre o ensino e sobre a aprendizagem.

\section{As possibilidades de uma Educação Física escolar inclusiva}

Nas análises que povoaram este trabalho, foi possível vermos os engendramentos das políticas inclusivas que não estavam sempre presentes, mas desde que foram incorporadas tornaram-se uma prática que atinge a todos os sujeitos, instâncias e instituições e, dentre elas, a escola. Pode-se dizer que as políticas inclusivas constituíram-se como um imperativo de Estado (LOPES; FABRIS, 2013) capaz de ser visto como uma verdade para a qual todos se inclinam e, na maioria das vezes, sem problematizá-las. Ao ser divulgada como uma política de acesso das minorias, é entendida como essencialmente benevolente. Contudo, na companhia de autores que se afinam na perspectiva dos Estudos Foucaultianos, procurei problematizar essa prática. A intenção não é negá-la, mas pensar em outros modos de fazê-la, de maneira que melhorem as condições que hoje são ofertadas aos sujeitos com deficiência.

Nessa discussão, a Educação Física escolar, que também é entrelaçada pelas políticas inclusivas, entra em cena. Para tal propósito, a análise de documentos que legitimam essa prática foi utilizada para mostrar quais fundamentos e objetivos são destinados aos educandos com deficiência na escola, em especial nas aulas de Educação Física. Com as reflexões, pode-se considerar que temos inúmeras indicações de que os aspectos que se relacionam ao ensino e a aprendizagem desse componente, no que diz respeito aos educandos com deficiência, ficam em suspeito. O foco está na condução das condutas, no aspecto moral e atitudinal e no gerenciamento dos riscos. Uma inclusão que, por vezes, se dá mais pelo social e pelo econômico, do que pela preocupação com aspectos referentes ao ensino e à aprendizagem dentro da escola.

$\mathrm{Na}$ esteira de pensamento de Foucault, é a ideia de desconfiar das verdades colocadas para tentar pensar de outro modo (TOURAINE, 2010) e fazer um exercício de contraconduta (FOUCAULT, 2010) estabelecendo práticas que realmente façam a inclusão ou, pelo menos, consigam enxergar na inclusão a lógica insidiosa de uma exclusão. Nessa medida, coloco-me como quem acredita na potencialidade que temos de realizar uma inclusão para além do trabalho com aspectos sociais, morais e com o gerenciamento de riscos, mas que conecte a prática docente ao ensino como uma potência no trabalho inclusivo que, para além de ver a diferença, consiga vivê-la e respeitá-la. 


\section{Referências}

AVELINO, N. Apresentação: Foucault e a Anarqueologia dos saberes. In: FOUCAULT, M. Do governo dos vivos: curso no Collège de France 1979- 1980: Excertos. SP/RJ: Achiamé, 2011.

BRASIL. Lei no 9.394, de 20 de dezembro de 1996. Estabelece as diretrizes e bases da educação nacional. Diário Oficial da União, Brasília, 23 jan. 1996.

BRASIL. Parâmetros Curriculares Nacionais: $3^{\circ}$ e $4^{\circ}$ ciclos do Ensino Fundamental Educação Física. Ministério da Educação e do Desporto, Brasília, 1997.

BRASIL. Manual do Programa Segundo Tempo. Ministério do Esporte, Brasília 2003.

BRASIL. Política Nacional de Educação Especial na Perspectiva da Educação Inclusiva. Ministério da Educação. SEESP. Brasília, 2008.

BRASIL. Resolução no 05 de 17 de dezembro de 2009 - Fixa as Diretrizes Nacionais para a Educação Infantil. Ministério da Educação. Brasília, 2009.

BRASIL. Resolução no 07 de 14 de dezembro de 2010 - Fixa as Diretrizes Nacionais para o Ensino Fundamental de 9 (nove) anos. Ministério da Educação. Brasília, 2010.

BRASIL. Resolução $\mathbf{n}^{\mathbf{0}} 02$ de 30 de janeiro de 2012 - Fixa as Diretrizes Nacionais para o Ensino Médio. Ministério da Educação. Brasília, 2012.

BRASIL. Diretrizes Curriculares Nacionais. Ministério da Educação. Brasília, 2013a.

BRASIL. Manual do Programa Atleta na Escola. Ministério do Esporte. Brasília, 2013b.

BRASIL. Manual de orientações esporte na escola. Ministério do Esporte. Brasília, 2013c.

CASTRO-GOMEZ, S. Historia de la gobernamentalidad: razón de Estado, liberalismo y neoliberalismo em Michel Foucault. Bogotá: Siglo del Hombre Editores; Pontificia Universidad Javeriana - Instituto Pensar; Universidad santo Tomás de Aquino, 2010.

DARIDO, S. C.; RANGEL, I. C. A. Educação Física na escola: implicações para a prática pedagógica. Rio de Janeiro: Guanabara Koogan, 2008.

ETCHEPARE, L. S.; PEREIRA, E. F.; ZINN, J. L. Educação física nas séries iniciais do ensino fundamental. Revista da Educação Física, Maringá, v. 14, n. 1, p. 59-66, jan./jun. 2003.

FIORIO, K.; LYRA, V. B. Educação física nos anos iniciais do ensino fundamental: um olhar sobre a formação profissional em um território contestado. In: ANPED SUL: Seminário de Pesquisa em Educação da Região Sul, 9., 2012, Caxias do Sul. Anais... Caxias do Sul: Ed. UCS, 2012.

FOUCAULT, M. As técnicas de si. In: FOUCAULT, M. Dits et écrits. v. 4. Paris: Gallimard, 1994. p. 783-813,.Traduzido por Karla Neves e Wanderson Flor do Nascimento. Disponível em: <http://revistas.pucsp.br/index.php/verve/article/viewFile/5017/3559>. Acesso em: 10 jun. 2015. 
FOUCAULT, M. O sujeito e o poder. In: RABINOW, P.; RABINOW, H. Michel Foucault: uma trajetória filosófica: para além do estruturalismo e da hermenêutica. Rio de Janeiro: Forense Universitária, 1995. p. 231-249.

FOUCAULT, M. A arqueologia do saber. 6. ed. Rio de Janeiro: Forense Universitária, 2001.

FOUCAULT. M. Em defesa da sociedade. São Paulo: Martins Fontes, 2005.

FOUCAULT, M. Vigiar e punir. 33. ed. Petrópolis: Vozes, 2007.

FOUCAULT, M. Nascimento da biopolítica. São Paulo: Martins Fontes, 2008a.

FOUCAULT, M. Segurança, território, população. São Paulo: Martins Fontes, 2008b.

FOUCAULT, M. História da sexualidade II: o uso dos prazeres. 14. ed. Rio de Janeiro/São Paulo: Graal, 2014.

FOUCAULT, M. A hermenêutica do sujeito. São Paulo: Martins Fontes, 2010.

GALLO, S. Uma apresentação: diferenças e educação, governamento e resistência. In: LOPES, M. C.; HATTGE, M. D. Inclusão escolar: conjunto de práticas que governam. Belo Horizonte, Autêntica, 2009. p. 7-12.

HATTGE, M. D. Performatividade e inclusão no movimento Todos pela Educação. 2014. 186 f. Tese (Doutorado em Educação) - Universidade do Vale do Rio dos Sinos, São Leopoldo, 2014.

LAVERGNE, R. F. A vontade de incluir: regime de verdade, recomposição das práticas e estratégias de apropriação a partir de um dispositivo de inclusão escolar em Fortaleza. 2009. 359 f. Tese (Doutorado em Educação) - Universidade Federal do Ceará, Fortaleza, 2009.

LOCKMANN, K. A proliferação das políticas de assistência social na educação escolarizada. 2013. 318 f. Tese (Doutorado em Educação) - Universidade Federal do Rio Grande do Sul, Porto Alegre, 2013.

LOPES, M. C. Políticas de inclusão e governamentalidade. Educação e Realidade, Porto Alegre, v. 34, n. 2, p. 153-170, maio/ago. 2009.

LOPES, M. C.; HATTGE, M. D. Inclusão escolar: conjunto de práticas que governam. Belo Horizonte: Autêntica, 2009.

LOPES, M. C.; FABRIS, E. H. Inclusão e educação. Belo Horizonte: Autêntica Editora, 2013.

LOPES, M. C.; VEIGA-NETO, A. Gubernamentalidad, biopolítica y inclusión. In: CORTÉS SALCEDO, R. A.; MARÍN-DÍAZ, D. L. (Comps.). Gubernamentalidad y educación: discusiones contemporâneas. Bogotá: IDEP, 2011. p. 105-122.

MACHADO, R. B. Paraolimpíadas e políticas de inclusão: formas de governar os corpos na sociedade e na escola. 2010. 151 f. Dissertação (Mestrado em Educação) - Universidade Luterana do Brasil, Canoas, 2010. 
MENEZES, E. C. P. A maquinaria escolar na produção de subjetividades para uma sociedade inclusiva. 2011. 189 f. Tese (Doutorado em Educação) - Universidade do Vale do Rio dos Sinos, São Leopoldo, 2011.

RECH, T. A emergência da inclusão escolar no Governo FHC: movimentos que a tornaram uma "verdade" que permanece. 2010. 186 f. Dissertação (Mestrado em Educação) - Universidade do Vale do Rio dos Sinos, São Leopoldo, 2010.

SILVA, T. T. Documentos de identidade: uma introdução às teorias do currículo. Belo Horizonte: Autêntica, 2011.

TOURAINE, A. Pensar de outro modo. Lisboa: Instituto Piaget, 2010.

UNESCO. Declaração Mundial sobre Educação para Todos: satisfação das necessidades básicas de aprendizagem. Jomtien, Tailândia, UNESCO, 1990.

UNESCO. Declaração de Salamanca sobre princípios, política e práticas na área das necessidades educativas especiais. Salamanca, Espanha, UNESCO, 1994.

VEIGA-NETO, A. Incluir para excluir. In: LARROSA, J.; SKLIAR, C. (Orgs.). Habitantes de Babel. Belo Horizonte: Autêntica, 2001. p. 105- 118.

VEIGA-NETO, A. Dominação, violência, poder e educação escolar em tempos de Império. In: RAGO, M.; VEIGA-NETO, A. (Orgs.). Figuras de Foucault. Belo Horizonte: Autêntica, 2006. p. 13-38.

VEIGA-NETO, A. Foucault e a educação. Belo Horizonte: Autêntica, 2007.

VEIGA-NETO, A. Pensar a escola como uma instituição que pelo menos garanta a manutenção das conquistas fundamentais da Modernidade. In: COSTA, M. V. (Org.). A escola tem futuro? Rio de Janeiro: DP\&A, 2003. p. 103-126.

VEIGA-NETO, A.; LOPES, M. Inclusão e governamentalidade. Educação \& Sociedade, Campinas, v. 28, n. 100, p. 947-963, out. 2007. DOI: 10.1590/s0101-73302007000300015

VEIGA-NETO, A.; LOPES, M. C. Há teoria e método em Michel Foucault? Implicações educacionais. In: CLARETO, S. M.; FERRARI, A. (Orgs.). Foucault, Deleuze \& Educação. Juiz de Fora: UFJF, 2010. p. 33-47. 